\title{
Action Research in English for Specific Purposes: English Language for the Medical Students in Bangladesh
}

ISSN: 2311-8636 (Print)

ISSN: 2312-2021 (Online)

DOI prefix: 10.18034/ajhal

Licensed:

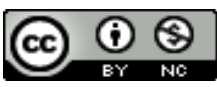

Source of Support: Nil

No Conflict of Interest: Declared

Email for correspondence:

liza.eng@diu.edu.bd

\section{Liza Sharmin}

Assistant Professor, Department of English, Daffodil International University, Dhaka, BANGLADESH

\section{ABSTRACT}

English for Specific Purposes (ESP) has flourished to meet the growing demand of the academic and professional learners. Since the tertiary level of education is the concern, ESP can be a way out to teach English as a second or foreign language. At the end of primary, secondary and higher-secondary level of English language education, a learner is expected to have a good command of the four skills of English language. Even though, if one fails to have the proficiency, $\mathrm{s} /$ he needs intensive teaching. ESP has very thoughtful and research-oriented arrangement for language teaching by needs analysis, formulation of goals and objectives, specific syllabus design, appropriate material development, effective teaching, and accurate evaluation.

In ESP, the practitioner, who is a needs analyst, is also a setter of goals and objectives, a syllabus designer, a material developer and a teacher as well as an evaluator. For this reason, there lies no gap among the steps of a whole project of language teaching. ESP learners are mature and more enthusiastic. In ESP, syllabus design depends on the analysis of the language used in the target area of learners. Sometimes, the syllabus designers consider the learners' opinions. Teaching materials are collected from the area of job or study of the learners. Interests, target and levels of previous knowledge of the ESP learners usually vary. Thus, for an individual group, a tailor-made ESP course is, therefore, suitable. The goal of the present action research is to design an English language course for the medical students.

In my professional life, I used to teach English language to the medical students. Since I taught them with general English language materials, I observed a gap between their target area and English language. "They cannot relate their achieved language knowledge to the medical context. For example, in a class, when they are asked to solve some exercises of active and passive voices, they can solve properly. But when they define terms like hypertension, or nervous system, they confidently use called/call/calls instead of is/are called. Medical students are really motivated by their subject specific texts. It is my assumption that, specific English language course can solve the problem by bridging the gap between their knowledge and their proficiency language." (Sharmin, L. -2011). On the basis of the information of data, collected from one preset questionnaire, I have analyzed needs and formulated an ESP course obtaining vocabulary, topic and examples from medical context. I found the classes more effective and interesting with these special materials. I have collected another set of data. I compared the data and found the results very optimistic.

Key Words: ESP, action research, medical students, English 


\section{INTRODUCTION}

The spirit of globalization and the growing communication in different fields have increased the necessity of using a single language worldwide. English not only as an international language, but also as a second language, is wide-spread and popular.

English for specific purpose (ESP) cherishes designing courses to meet the learner's needs. Due to the professional requirements, the learners need particular course designing for developing and practicing English language skills. In addition to that, the materials for teaching language should be relevant for the learners. Taking into account their needs, the designer will specify the goals and objectives of the course.

The goal of ESP courses is to equip the learners with English language skill or skills so that they can face the situation they experience in their academic or professional life. For achieving the goals, a thoughtful syllabus designing and material development is essential on the basis of the learners needs. So, analyzing their needs is the most vital issue. Currently, needs analysis researches have become an interesting point in exploring ways of improving the competence of learners by using a tailor-made course? Medical students need to achieve competence in all of the four skills of English language. This research aims to determine the needs of the medical students so that on the basis of the needs, an ESP syllabus can be designed for the medical students.

\section{Procedure}

"The first major and basic step in the act of designing an ESP course is needs analysis. It is a process to specify or determine exactly why the learners need English language proficiency. Hutchinson and Waters (1987), and Dudley - Evans and Jo ST John (1998), define needs in terms of 'target needs' (i.e. what the learner needs to do in the target situation ) and learning needs (i.e. what the learner needs to do in order to learn). According to Hutchinson and Waters (1987), and Dudley - Evans and Jo ST John (1998), the best methodology for specifying the target need of any particular group of students is to use such methods as questionnaires, follow-up interviews, collection of authentic work place texts, and visit to the workplaces." (Sharmin, L. -2011)

As a continuous process, "I have collected data with a preset questionnaire and through interviewing the medical students of 1st semester, Gonoshasthaya Somaj Vittik Medical College, Gono Bishwabidyalay. I have analyzed the information to find out the specific problems. I have also interviewed some distinguished teachers of the institution, whose views and ideas, remarks and opinions in this regard have been analyzed and evaluated so that we can reach towards some conclusion." (Sharmin, L. -2011)

"During the first few years of my teaching, I taught the medical students with General English language materials and found that there is a gap between their target area and English language. They cannot relate their achieved English language knowledge to the medical context. Taking into consideration the problems of the medical students, I formulated an ESP course obtaining vocabulary, topics, and examples from the medical scenario and found the classes more effective and interesting with these special materials. I have collected another set of data. Later, I compared the data and found the results very positive." (Sharmin, L. -2011) 


\section{SUBJECT/ SAMPLE}

Sample is usually a subset of a population. To determine the necessity of an ESP course for the medical students in Bangladesh, I have selected Gonoshasthaya Somaj Vittik Medical College, Gono Bishwabidyalay, which is one of the prominent private medical colleges in Bangladesh. Here medical students need to complete courses in English language in two consecutive semesters of six months. I have taught English language to the students of 3rd, 4 th, 5th, 6th, 7th, 8th and 9th batches of the students of this medical college. All of them are population, as a population is the entire group of people that a particular study is interested in. But I have selected 80 students of this medical college as the sample of my research program by Random sampling where each person in the population has an equal chance of being selected into the sample. Out of 80 students, 38 are females and 42 males. All of them scored Grade A or A+ in their SSC and HSC examinations.

\section{INSTRUMENTATION}

I have collected the data with a preset questionnaire and through interviewing the medical students of Gonoshasthaya Somaj Vittik Medical College, Gono Bishwabidyalay. I have also interviewed some distinguished teachers of the institution, whose views and ideas, and remarks and opinions in this regard have been analyzed and evaluated so that some conclusion could be reached out of these. I have prepared a questionnaire to collect data since I needed to evaluate the current level of language proficiency of the target group of learners. From the written document of the questionnaire, I have tried to identify the fluency and the common error they have made. Through the interview session, I have measured their ability in speaking and listening skills.

\section{Data Collection}

In Wikipedia the free Encyclopedia, data collection is explained as; "Data collection is a term used to describe a process of preparing and collecting data - for example as part of a process improvement or similar project." The goal of data collection is to look for information for preserving, taking decisions and for sharing information to the others. I prepared a questionnaire and asked the sample to fill it up in complete sentences. Some area-related simple questions were set in the questionnaire so that they could answer in English. Afterwards, I analyzed the answers for identifying the mistakes they made. And, I did it to find out the weaknesses they have in English language proficiency. It also helped me to determine the lacks of the students.

\section{Data ANALYsis}

English is the medium of instruction in all medical colleges in Bangladesh. The students of these colleges depend on their skills in English language of their text books and relevant materials while they study, and take the examinations. This research aims to pick out the problems that the medical students face while they use skills of English language. There were 14 questions in the questionnaire. The students were asked to answer the questions in a complete sentence/ sentences.

\section{DISCUSSION}

When the information of the data was collected and analyzed, it was found that in the very first question, they made three types of mistakes. Only 34\% students could answer properly. (Sharmin, L. -2011). The first question was: "How long have you been studying 
in this medical college?" (Sharmin, L. -2011). 20\% students answered: "I am studying ----" (they did not write: I have been studying.....). 16\% students answered: "for nine month or three month" (they forgot to add's' after the word month). 20\% of them mentioned about the duration only though they were instructed to give the answer in complete sentence. (Sharmin, L. -2011)

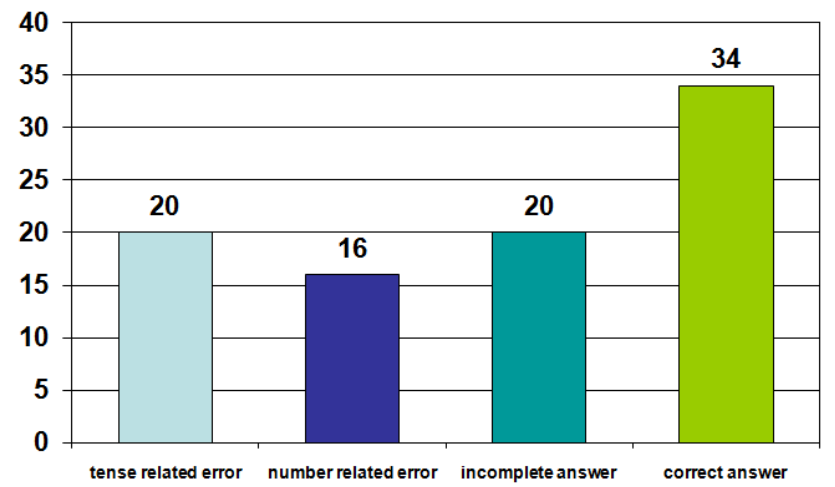

Figure 1: Variable-related error analysis I (Sharmin, L. -2011)

The second question was: "Why do you want to be a doctor?" (Sharmin, L. -2011). Only $24 \%$ students could answer satisfactorily

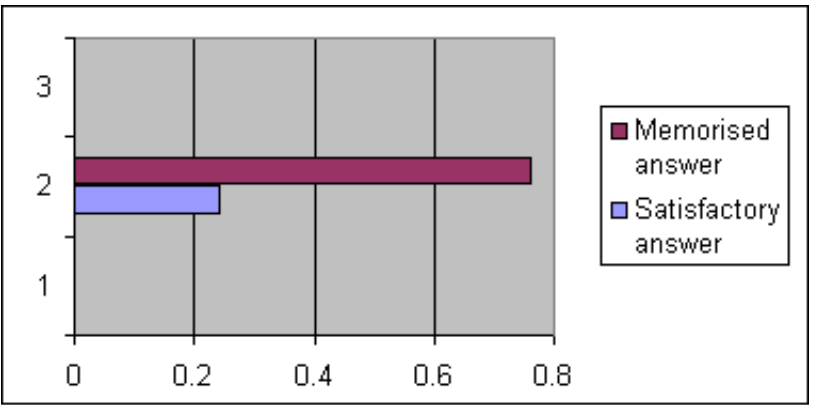

Figure 2: Figure showing the ratio of satisfactory and dissatisfactory answers (Sharmin, L. -2011)

The rest of the students just copied one single common answer: 'to serve the poor people.' (Sharmin, L. -2011). But, when they were asked individually the same question in their mother tongue, they answered 'It is the interest of my parents that inspired me to study medicine.' 'My heart bleeds when I see people suffering from diseases. Being a doctor I will serve them.' 'I'll help the poor and I'll never take money from the poor. The rich will feed me and the poor will pray for me.' 'My father is a doctor, so I want to be a good doctor like him' (Sharmin, L. -2011). This indicates that the learners' ideas are clear, but they could not express those correctly because of their lack in the fluency in English. (Sharmin, L. -2011).

The third question was: "The profession you have chosen is very challenging and tough. So many responsibilities are there. Do you think that you are competent enough to face all the challenges successfully?" 74\% students answered: - "Yes I think I am confident enough. ... 


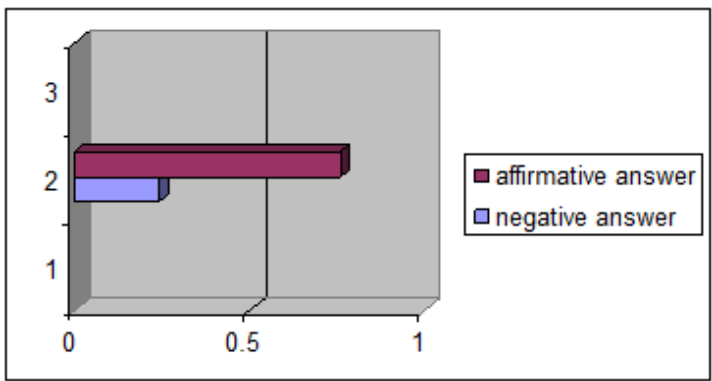

Figure 3: Figure showing the ratio of affirmative and negative answers

But, the remaining number of students-26\%- answered: “No,. ." It means that either they are not confident as they have just begun their course, or they have not understood the question.

The fourth question was: "Among your three major subjects, which one is your favorite?" 34\% students answered: "Among my three major subject." (They forget to use's'after the word subject which is a countable noun). 14\% students answered: "My favorite subject Anatomy / Physiology / Biochemistry" (they forgot to use 'the auxiliary verb'). 4\% students answered: "My favorite subject is Anatomy, Physiology and Biochemistry." Perhaps they did not understand the meaning of the question. The rest of the students $56 \%$ - answered correctly.

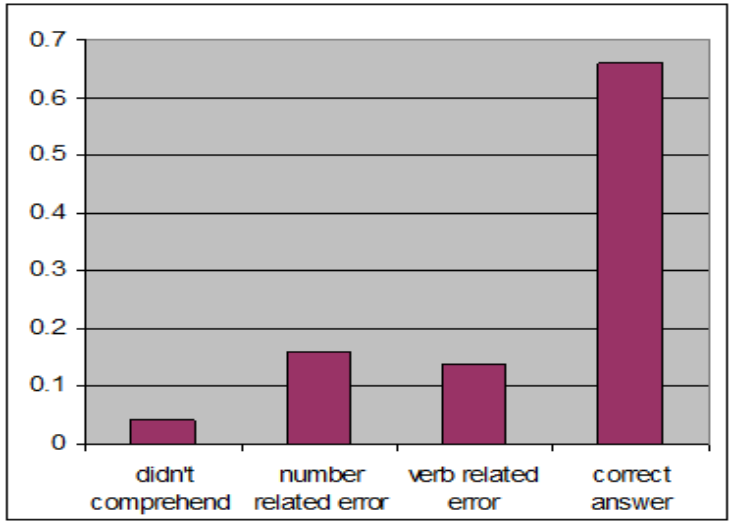

Figure 4: Variable-related error analyses II

The fifth question was: "What does Anatomy deal with?" $46 \%$ of the students wrote: 'Anatomy deal with........' (did not write deals). The rest of the students, however, could answer properly.

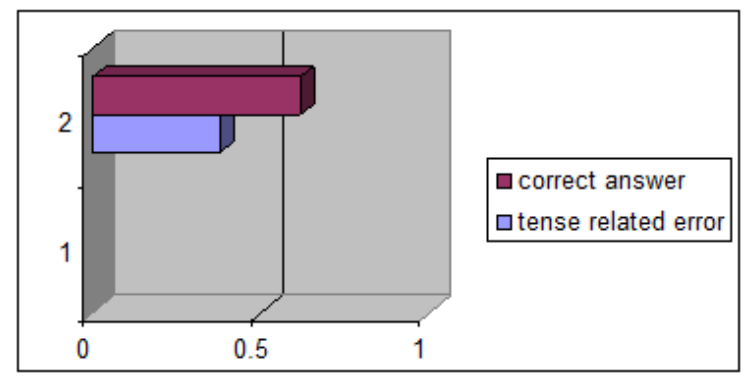

Figure 5: Variable-related error analysis III 
The sixth question was, "What are the differences between Anatomy and Physiology?" While giving the answer, $30 \%$ students forgot to use any auxiliary verb after the main verb, $20 \%$ of them used an inappropriate auxiliary verb in their answers. (They used is instead of are). The remaining $50 \%$ of the students could answer appropriately.

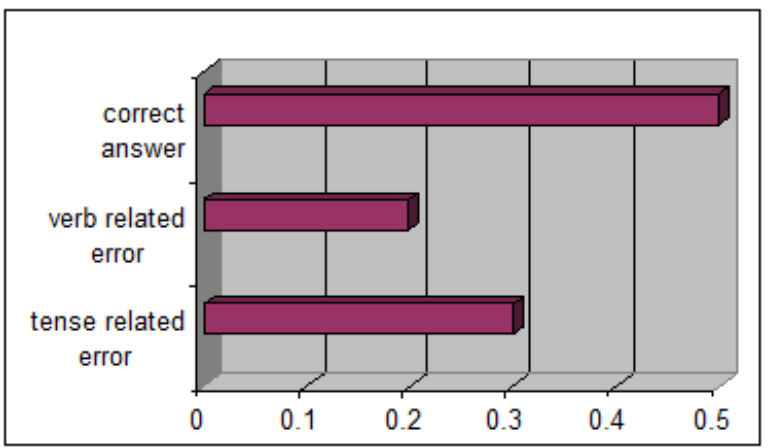

Figure 6: Variable-related error analysis IV

The seventh question was: "What are the subject- matters of Biochemistry? Why is it important for medical students?" 20\% students, when giving the definition of the term they referred to, used called instead of are called. $22 \%$ of them made a tense-related error. The rest of the students could answer satisfactorily.

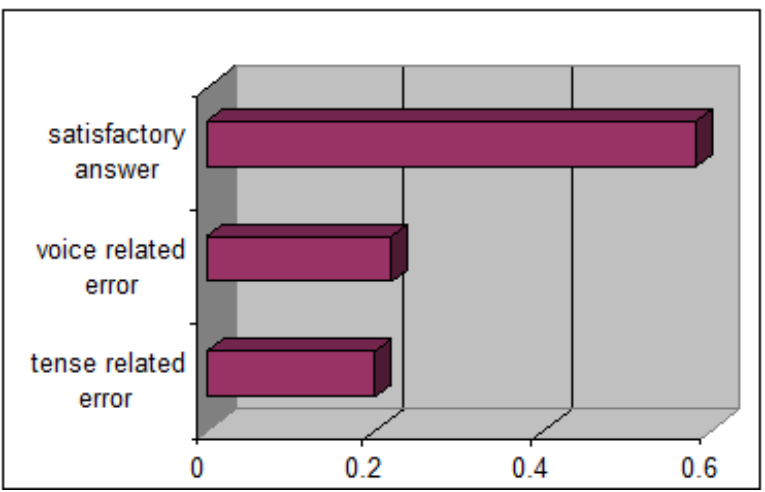

Figure 7: Variable-related error analysis V

The eighth question was: "Do you think that English language teaching is essential for the medical students in Bangladesh? Why do you think so? $40 \%$ students could express their ideas in answering the question.

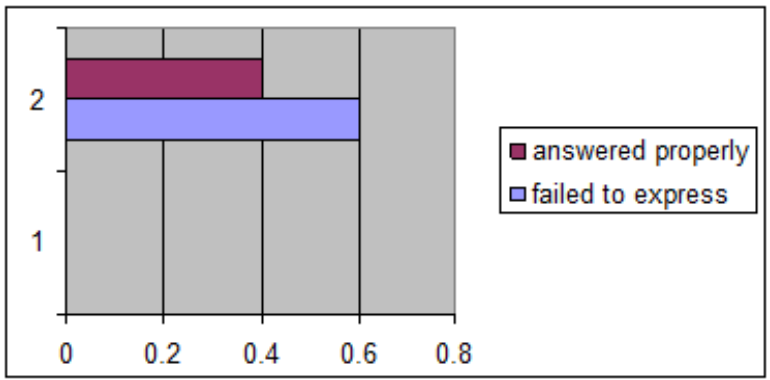

Figure 8: Figures showing the ratio of correct and incorrect answers 
The rest of them give an incomplete answer like 'medical college course in English'. But when they are asked to give the answer orally, they said the following:

- In all the medical colleges in Bangladesh, English is used as medium of instruction.

- Medical books are available in English.

- All the medical journals, periodicals are also available in English.

- During examinations, they must answer in English, etc.

The ninth question was: "How can your English language proficiency help you in your main courses?" 46\% students could not express their thought satisfactorily. $10 \%$ of them answered properly.

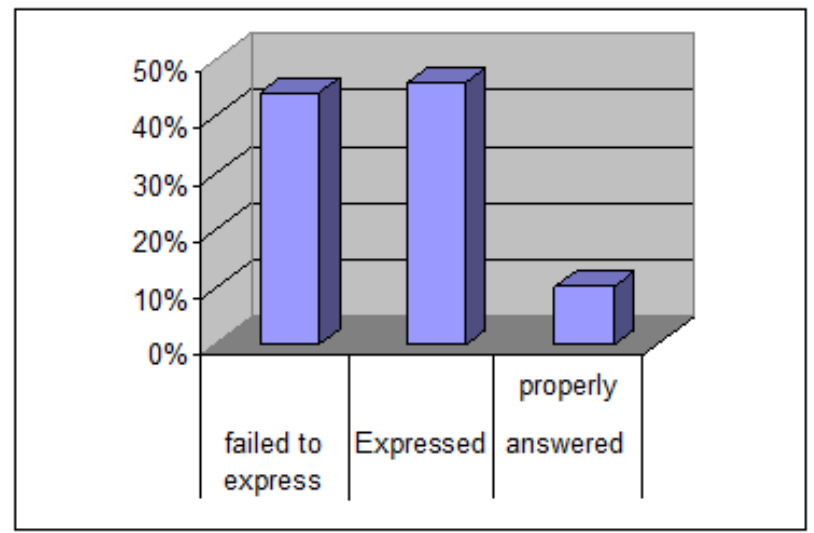

Figure 9: Figure showing the ratio of proper and unsatisfactory answers

The rest of them could not express their ideas due to lack of vocabulary and knowledge in sentence structure. The tenth question was: "What sort of English teaching can be helpful for the medical students?" 30\% students answered that Communicative Language Teaching can be helpful for them (They are familiar with the term since they studied CLT in their HSC level). 38\% students answered: 'medical related English'. 24\% students answered: 'English language course'. 18\% students did not give any answer at all.

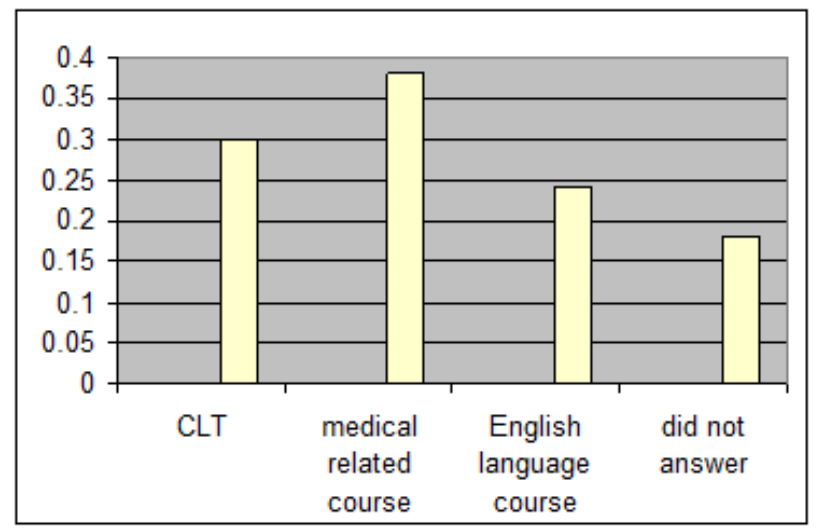

Figure 10: Figure showing tense-related errors

The eleventh question was: "I think most of the students know more or less grammar, but the problem is to apply grammar into practical purposes. Do you agree with me?" $98 \%$ 
students answered: 'Yes, I agree.' 2\% students answered: 'No, I do not. ' $1 \%$ student answered: 'No, I am not agree.'

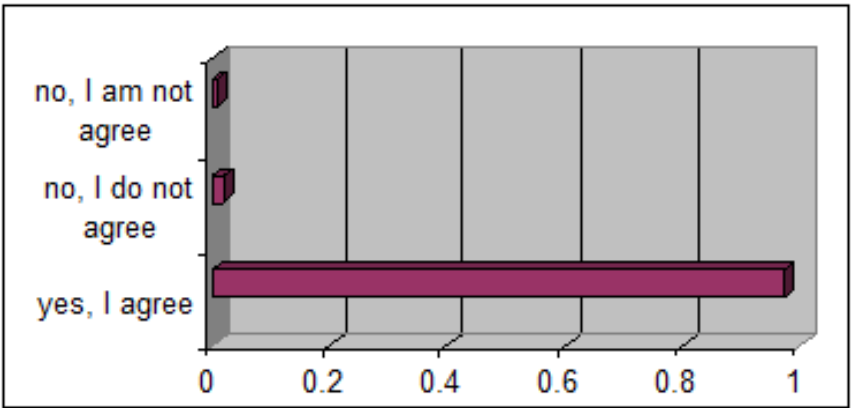

Figure 11: Figure showing the ratio of complete and incomplete answers- I

The twelfth question was: "Do you think that the students also suffer from lack of competent vocabulary?" $20 \%$ of the students answered: Yes'. And, the rest of the students could answer satisfactorily.

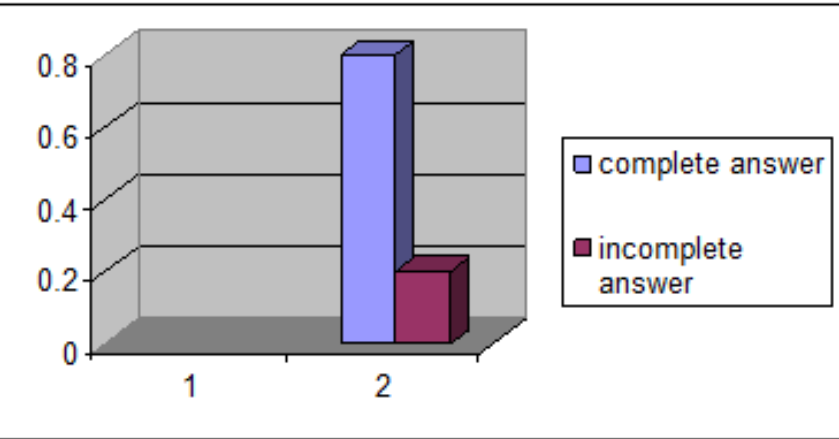

Figure 12: Figure showing the ratio of complete and incomplete answers- II

The thirteenth question was: "Do you think that a particular medical English language course (consisting of health Science area related vocabulary and grammatical aspects with context related examples) can help you to improve your English language skills?" 20\% of the students answered; 'yes'. And the rest of the students could answer satisfactorily.

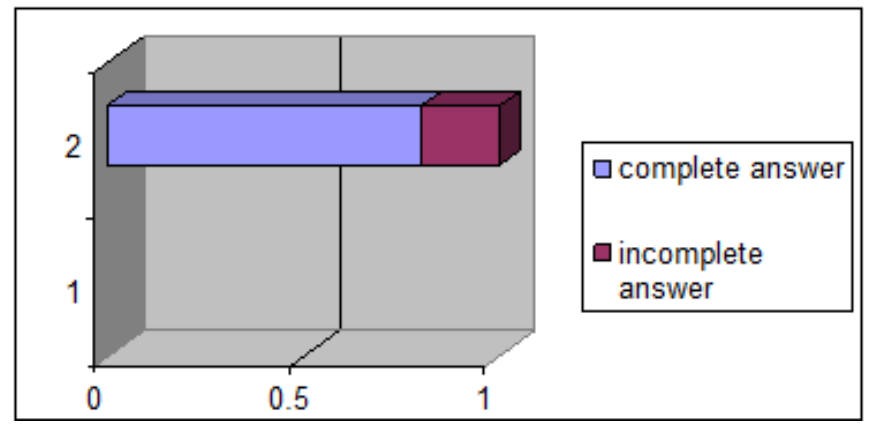

Figure 13: Figure showing the ratio of complete and incomplete answers- III

The fourteenth question was: "What other initiatives can we take for developing English language skills of the medical students in Bangladesh." $4 \%$ of the students answered: "in bangladesh,' 'english language'. 
$14 \%$ of them answered: If you will give them chance they are fine in English. Many initiatives can take, they can be developed.

10\% answered: The entire medical student, Many initiative, there are some English language course

8\% answered: to development, for improve, to improve I English language skills.

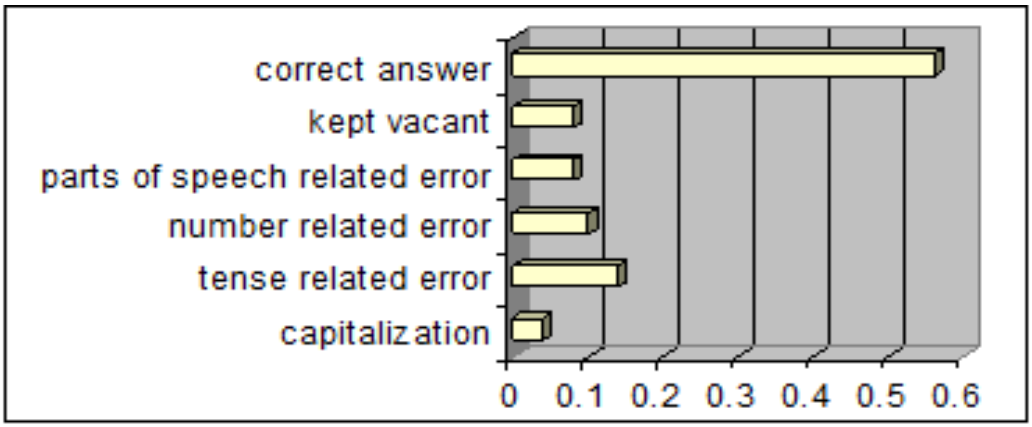

Figure 14: Variable-related error analyses VI

$8 \%$ of the students did not answer the question. And, the rest of the students could answer satisfactorily.

If we summarize the data analyzed above, we can see that the following number of students is suffering from some particular problems. For example:

Total number of students $=80$

Students suffering from fluency $=76 \%$

The number of male students having problems is $76 \mathrm{X} 42 / 100=31.92 \%$

In the same way,

The number of female students having problems is 76 X38 $/ 100=28.88 \%$

Table 1: table showing the ratio of average variable-related errors found among the medical students before taking the ESP course

\begin{tabular}{|l|c|c|c|c|c|c|c|}
\hline $\begin{array}{l}\text { Variables } \\
\text { /category }\end{array}$ & Fluency & $\begin{array}{c}\text { Tense } \\
\text { related } \\
\text { error }\end{array}$ & $\begin{array}{c}\text { Verb } \\
\text { related } \\
\text { error }\end{array}$ & $\begin{array}{c}\text { Voice } \\
\text { related } \\
\text { error }\end{array}$ & $\begin{array}{c}\text { Parts of } \\
\text { speech } \\
\text { related error }\end{array}$ & $\begin{array}{c}\text { Structure } \\
\text { (sentence) } \\
\text { related error }\end{array}$ & $\begin{array}{c}\text { Capitali zation } \\
\text { related } \\
\text { error }\end{array}$ \\
\hline Total & $76 \%$ & $46 \%$ & $30 \%$ & $20 \%$ & $8 \%$ & $54 \%$ & $4 \%$ \\
\hline Male & $31.92 \%$ & $19.32 \%$ & $14.4 \%$ & $8.4 \%$ & $3.36 \%$ & $22.68 \%$ & $1.68 \%$ \\
\hline Female & $28.88 \%$ & $17.48 \%$ & $11.4 \%$ & $7.6 \%$ & $3.04 \%$ & $17.28 \%$ & $1.58 \%$ \\
\hline
\end{tabular}

\section{FINDINGS AND CONCLUSION}

Analyzing the samples' answers carefully, I have identified the areas where they are facing problems. In the light of analysis, it can be said that fluency in both speaking and writing, lack of adequate vocabulary, and insufficient practice and knowledge of grammatical rules are some basic problems. I have highlighted the figure of error in the form of percentage through graphs. Finally, I have formulated a table where problematic areas are exposed clearly. 
After analyzing the problems, I have designed a specific Medical English language course. The syllabus I have designed for the medical students is rather a mixed type. It can be called a skill-based since all the four skills are highlighted here. We can also call it a taskbased since each of the items including grammatical aspects is explained with materials from their task-based area, i.e. from medical context.

At Gonoshasthaya Somaj Vittik Medical College, the students need to complete two semesters of English Language Course. Each course is of 3 credits and in each semester they need to attend 45 classes. The duration of each class is 50 minutes. This syllabus is designed for $45 \times 2=90$ classes. Selection and organization of contents and materials are rather appropriate and thoughtful.

To improve speaking and listening skills, some context -oriented dialogues are composed to be used for role-playing. These dialogues could be recorded in the audio-oral system for the use in the language laboratory. Some context-related questions with answers are included in the course to be practiced in class situation. Topics like Brain-drain, EPI, Maternal mortality, Duties of a medical professionals, Hospital management, Occupational health, Stress, Oedema, Blood circulation system, Hygiene, AIDS, Cancer, etc. are included in the course to use. Reading comprehension can be an effective means of practicing reading skill as well as the other skills in a classroom situation. So, some interesting and informative medical science related texts have been collected for comprehension with brain-storming questions. For developing writing skill, I have included some model paragraphs like Human brain, Bird Flu, Arsenic problem, etc. I have included some model applications which are very much relevant to the study area of the medical students. Again, for improving active skills like speaking and listening, I have included some structural elements, such as for reviewing tense system, formation of parts of speech, structure of clauses, sentences, use of modals, voices etc. Thus, the ESP syllabus for the medical students was designed with the hope that at the end of the course, the students will be able to understand and use correct and good English in their professional and personal life.

As a part of an action research, I have personally taught the medical students of Gonoshasthaya Somaj Vittik Medical College for two semesters. Since I have collected the materials from the academic area of the medical students, they were highly motivated and interested. After completion, I have taken another set of data. After analyzing that set of data, I summarized the data into another table. Here I want to mention that, in this procedure, I have, time to time, discussed with the teachers of Anatomy, Physiology, Biochemistry, Community Medicine, whose suggestions also helped me a lot beside the remarks of my colleagues in the Department of English.

Table 2: table showing the ratio of average variable-related errors found among the medical students after taking the ESP course (Sharmin, L. -2011)

\begin{tabular}{|c|c|c|c|c|c|c|c|}
\hline $\begin{array}{c}\text { Variables } \\
\text { category }\end{array}$ & Fluency & $\begin{array}{c}\text { Tense } \\
\text { related } \\
\text { error }\end{array}$ & $\begin{array}{c}\text { Verb } \\
\text { related } \\
\text { error }\end{array}$ & $\begin{array}{c}\text { Voice } \\
\text { related } \\
\text { error }\end{array}$ & $\begin{array}{c}\text { Parts of } \\
\text { speech } \\
\text { related error }\end{array}$ & $\begin{array}{c}\text { Structure } \\
\text { (sentence) } \\
\text { related error }\end{array}$ & $\begin{array}{c}\text { Capitalization } \\
\text { related } \\
\text { error }\end{array}$ \\
\hline Total & $16 \%$ & $10 \%$ & $6 \%$ & $3 \%$ & $8 \%$ & $12 \%$ & $2 \%$ \\
\hline Male & $6.72 \%$ & $4.2 \%$ & $2.52 \%$ & $1.26 \%$ & $1.68 \%$ & $5.04 \%$ & $0.84 \%$ \\
\hline Female & $6.08 \%$ & $3.8 \%$ & $2.28 \%$ & $1.14 \%$ & $1.52 \%$ & $4.56 \%$ & $0.64 \%$ \\
\hline
\end{tabular}

When I compared the ratio of the both tables, I found the result satisfactory. Thus, for the medical students, this tailor-made ESP course is suitable, motivating, and attractive. 


\section{REFERENCES}

Dudley Evans, T., \& St. John, M. (1998): Developments in ESP: A multi-disciplinary approach. Cambridge: Cambridge University Press.

Hutchinson, T. \& Waters, A. (1987): English for specific purposes. Cambridge: Cambridge University Press.

Richterich, R. \& Chancerel, J. L. (1980). Identifying the needs of adults learning a foreign language, Oxford: Pergamon Press

Sharmin, L. (2011). Analyzing 'needs' for designing a specific English Language course for medical students in Bangladesh, Stamford Journal of English, 6,234-244

\section{APPENDIX}

\section{Questionnaire}

The questionnaire is designed to collect data for analyzing the problems of English Language skills among the medical students of Bangladesh for developing an ESP course for them. The students are requested to answer in complete sentence/ sentences. Your cooperation will be highly appreciated.

Name:

Name of the Medical College:

Batch:

Question no. 1. How long have you been studying in this medical college? (Sharmin, L. -2011) Answer:

Question no. 2.Why do you want to be a doctor? (Sharmin, L. -2011)

Answer:

Question no. 3. The profession you have chosen is very challenging and tough. So many responsibilities are there. Do you think that you are competent enough to face all the challenges successfully?

Answer:

Question no. 4. Among your three major subjects, which one is your favorite?

Answer:

Question no. 5. What does Anatomy deal with?

Answer:

Question no. 6. What are the differences between Anatomy and Physiology?

Answer:

Question no. 7. What are the subject- matters of Biochemistry? Why is it important for medical students?

Answer:

Question no. 8.Do you think that English language teaching is essential for the medical students in Bangladesh? Why do you think so?

Answer: 
Question no. 9. How can your English language proficiency help you in your main courses?

Answer:

Question no.10: What sort of English teaching can be helpful for the medical students?

Answer:

Question no. 11: I think most of the students know more or less grammar, but the problem is to apply grammar into practical purposes. Do you agree with me?

Answer:

Question no. 12: Do you think that the students also suffer from lack of competent vocabulary?

Answer:

Question no. 13: Do you think that a particular medical English language course (consisting of Health Science area related vocabulary and grammatical aspects with context related examples) can help you to improve your English language skills?

Answer:

Question no. 14: What other initiatives can be taken to develop English language skills of the medical students in Bangladesh.

Answer:

Thank you.

\section{Biography}

Liza Sharmin has completed her B A (Hons.) and M A in English Literature and Language from Jahangirnagar University, Bangladesh. She is an Assistant Professor, Department of English, Daffodil International University. She had previously been teaching in the Department of English Language and Literature as a Senior Assistant Professor at Gono Bishwabidyalay (University) for fourteen years. She has been teaching English Literature, ESP and Linguistics to the students majoring in English. Her research area is Applied Linguistics and ESP. She has presented her papers in various national and international conferences. She is very interested in translation. Some of her translations were published in national dailies. She has published books on English Language and ESP, and also research papers in academic journals.

Publish Online and Print Version Both

Online ISSN: 2312-2021

Google Scholar: https://goo.gl/eozEWi 